\title{
Internalisasi Pendidikan Agama Bagi Remaja Melalui Majlis Ta'lim
}

\author{
Ahmad Sanusi' ${ }^{1}$, Hamdanah ${ }^{2}$, Surawan ${ }^{3}$ \\ ${ }^{123}$ AIN Palangka Raya, Kalimantan Tengah, Indonesia \\ Email: Sanusiucie99@gmail.com¹, hamdanahilham@gmail.com², surawan@iain- \\ palangkaraya.ac.id ${ }^{3}$
}

\begin{abstract}
This article is the result of observations in Darussalam Danu roasted that there are special security studies carried out specifically for adolescents. This study was carried out in an effort to provide spiritual oases for young people in the midst of global challenges. This study was aiming 1) grabbing the inteningization process of adultery education of adolescent education through the Ta'lim Assembly and 2) displacing supporting factors and the inhibition of internalization of the values of the United Darussalam adolescent religion. The research uses descriptive analysis method, development technique of collecting in the form of interviews, observation and documentation. The subject in this study was an ustadz who taught at the Ta'lim Assembly, while informants were teenagers, adolescents who attended Majlis Ta'lim, community leaders and peers. Informant complaints using purposive sampling. Data application techniques use triangulation of sources and techniques. Reason for data analysis includes reduction, displaying and verification. The results of the study represented that 1) internalization of adultery education of adolescent education to instill the tilapia of religious religious values to adolescents, the method was used cheap modeling model and demonstration, data on the values of religion, worship, and morality. 2) Popular factors include the capacity of qualified teachers and communities. Meanwhile, inhibitory factors include the influence of negative association of adolescent associations and limited facilities of Majlis Ta'lim.
\end{abstract}

Keywords: Internalization Values, Religious Education, Adolescent

\begin{abstract}
Abstrak
Artikel ini adalah hasil dari observasi di Darussalam Danau Panggang bahwa ada kegiatan kajian keagamaan yang dilakukan secara khusus untuk remaja. kajian ini dilakukan sebagai upaya untuk menyediakan oasis spiritual bagi kaum muda di tengah-tengah tantangan global. Penelitian ini bertujuan 1) menggambarkan proses intenialisasi nilai-nilai pendidikan agama remaja melalui Majelis Ta'lim dan 2) menggambarkan Faktor-faktor pendukung dan penghambat internalisasi nilai-nilai pendidikan agama remaja di Desa Darussalam Kecamatan Danau Panggang. Penelitiannya menggunakan metode deskriptif analisis, dengan teknik pengumpulan data dalam bentuk wawancara, observasi dan dokumentasi. Subjek dalam penelitian ini adalah seorang Ustadz yang mengajar di Majelis Ta'lim, sedangkan informan adalah orang tua remaja, remaja yang menghadiri majlis
\end{abstract}

Al-Fikri: Jurnal Studi dan Penelitian Pendidikan Islam

Vol. 04 No. 02 (2021) : $117-126$

Available online at http://jurnal.unissula.ac.id/index.php/fikri/issue/archive 
Ta'lim, tokoh masyarakat dan teman sebaya. Teknik penentuan informan menggunakan purposive sampling. Teknik aplikasi data menggunakan triangulasi sumber dan teknik. Tahapan analisis data yang meliputi reduksi, display dan verifikasi. Hasil penelitian menunjukkan bahwa 1) internalisasi nilainilai pendidikan agama remaja bertujuan untuk menanamkan nilai-nilai agama kepada remaja, metode yang digunakan seperti model perkuliahan dan demonstrasi, sedangkan bahan yang diajarkan kepada remaja bersumber dari Kitab Hadits Riyadus Shalihin dan Kitab Hiyadatus Salikin yang berisi nilai-nilai agama, ibadah, dan moralitas. 2) Faktor pendukung meliputi kapasitas guru yang berkualifikasi dan lingkungan masyarakat. Sementara itu, faktor penghambatan meliputi pengaruh pergaulan negatif asosiasi remaja dan fasilitas terbatas dari majlis ta'lim.

Kata Kunci : Internalisasi Nilai-Nilai, Pendidikan Agama, Remaja.

\section{Pendahuluan}

Masa remaja merupakan masa yang penuh dengan tantangan dan banyak condong ke arah negatif. Tentu ada banyak yang dihadapi oleh remaja, seperti emosi yang kurang stabil, sering tidak percaya diri, merasa selalu benar, ingin mandiri karena sudah merasa dewasa, ingin selalu tampil menarik, ingin dilirik dan sebagainya. Maka dengan menanamkan nilai-nilai pendidikan keagamaanlah, remaja dapat mengendalikan diri, terkhusus bagi para remaja yang menyukai tantangan dan hal-hal baru (Ghufron Bahtiar, 2015). Hal ini karena pada masa remaja merupakan masa yang tepat untuk diberikan arahan dan bimbingan keagamaan untuk membentuk remaja menjadi remaja yang lebih baik.

Sekarang ini, sangat jarang ditemui masyarakat yang peduli atau bahkan memberikanfasilitas kepada masyarakatnya dalam hal pendidikan keagamaan, akan tetapi berbeda halnya dengan Desa Darussalam yang mana di sana terdapat dua mushala dan satu masjid dalam satu desa untuk tempat beribadah. Bahkan, ketiganya ini juga dimanfaatkan sebagai tempat kegiatan keagamaan yang dilakukan secara bergantian baik pagi ataupun malam untuk masyarakat umum. Kegiatan keagamaan ini dilakukan untuk menanamkan nilai-nilai pendidikan keagamaan kepada masyarakat umum, baik orang tua, remaja bahkan anak-anak.

Salah satu faktor pembentuk pengetahuan, sikap dan perilaku beragama pada remaja adalah faktor lingkungan terutama teman sebaya. Kelompok teman sebaya memberikan peluang yang besar dalam membentuk religiusitas pada remaja melalui proses konformitas (Warsiyah, 2018). Kesadaran terhadap pentingnya komunitas teman sebaya

Al-Fikri: Jurnal Studi dan Penelitian Pendidikan Islam

Vol. 04 No. 02 (2021) : $117-126$

Available online at http://jurnal.unissula.ac.id/index.php/fikri/issue/archive 
yang positif dan memberikan dampak yang baik terhadap remaja di sadari oleh penggagas majlis ta'lim yang digagas oleh ustadz yang berinisial HR. Kegiatan majelis ta'lim dilaksakanan dua kali dalam seminggu di rumahnya. Tujuan kegiatan pendidikan keagamaan ini adalah untuk menanamkan nilai-nilai pendidikan keagamaan kepada remaja untuk bekal mereka dalam beribadah dan bisa mengamalkan ilmu dalam kehidupan sehari-hari.

Berdasarkan hasil observasi, bahwa para remaja di Desa Darussalam selalu datang lebih awal ke mushala sebelum azan dikumandangkan. Para remaja juga berpuasa wajib di bulan Ramadhan dan puasa sunnah di bulan lainnya. Mereka juga terlibat dalam kegiatan ibadah di masjid seperti mengikuti pembacaan yasin rutin di malam Jum'at setelah sholat Maghrib dan pembacaan dalail setelah sholat Subuh pada hari jum'at di masjid. Kemudian mereka juga ikut berperan membantu kegiatan yang ada di masyarakat (Observasi, pada tanggal 30 Agustus 2020 pukul 18.20 WIB)

Melihat dari hal tersebut dan beberapa kegiatan-kegiatan yang remaja lakukan di Desa Darussalam. Peneliti ingin mendeskripsikan dan menjelaskan penanaman nilai-nilai pendidikan keagamaan remaja melalui kegiatan yang dilaksanakan di rumah ustadz tersebut dengan judul "Internalisasi Nilai-Nilai Pendidikan Keagamaan Remaja Melalui Majelis Ta'lim di Desa Darussalam Kecamatan Danau Panggang Kabupaten Hulu Sungai Utara Kalimantan Selatan".

\section{Metode}

Dalam penelitian ini menggunakan desain deskriptif kualitatif. Tempat penelitian adalah Desa Darussalam, Kecamatan Danau Panggang Kabupaten Hulu Sungai Utara Kalimantan Selatan. Waktu Penelitian adalah 18 Februari sampai 18 April 2021. Target atau subjek penelitian adalah salah seorang ustadz dan informannya terdiri dari orang tua remaja, remaja, tokoh masyarakat dan teman sejawat. Metode pengumpulan data menggunakan wawancara, observasi dan dokumentasi. Dengan teknik Triangulasi sumber dan triangulasi. Tahapan analisis data yang meliputi reduksi, display dan verifikasi.

\section{Hasil dan Pembahasan}


Internalisasi nilai-nilai pendidikan keagamaan remaja melalui majelis ta'lim adalah merupakan suatu proses yang dilakukan dalam menanamkan nilai-nilai pendidikan keagamaan yang diinternalisasikan kepada remaja. Menurut Ihsan internalisasi adalah sebagai upaya yang dilakukan untuk memasukkan nilai-nilai ke dalam jiwa seseorang (Nuraini Nuraini, 2019). Sedangkan menurut Hamdanah nilai adalah suatu yang dapat dijadikan sebagai rujukan (Hamdanah and Rinaldy, 2017)

Internalisasi nilai adalah sesuatu yang ditanamkan dalam diri seseorang baik berupa nilai atau sikap melalui pembinaan secara mendalam. Proses internalisasi nilai-nilai pendidikan keagamaan remaja melalui majelis ta'lim yang dilakukan oleh ustadz HR meliputi tujuan internalisasi nilai, metode internalisai nilai dan jenis nilai yang diinternalisasikan sebagai berikut:

Pertama tujuan internalisasi nilai bertujuan agar remaja memiliki sikap, dan perilaku yang baik serta menjadikan remaja yang beradab dan berakhl akul karimah. Tentunya dengan melihat tujuan ini, sesuai dengan aturan menurut Undang-undang Nomor 55 Tahun 2007 tentang Pendidikan Diniyah Nonformal Pasal 23 butir 1 bahwa "Majelis Taklim atau nama lain sejenis bertujuan untuk meningkatkan keimanan dan ketakwaan kepada Allah SWT dan akhlak mulia peserta didik serta mewujudkan rahmat bagi alam semesta".

Kedua metode internalisasi nilai Pada kegiatan majelis ta'lim ada beberapa metode yang digunakan dalam internalisasi nilai yang pertama metode keteladanan. Hal ini terlihat dari figur sang ustadz yang memiliki kepribadian yang sangat baik. Sehingga dapat menginspirasi para remaja untuk mengikuti majelis ta'lim di rumah beliau. Hal ini senada dengan pendapat Hartini dalam Muslimah bahwa metode keteladanan merupakan metode yang sangat efektif dan meyakinkan (Muslimah, 2015).

Adapun yang membuat para remaja aktif menghadiri majelis ta'lim karena ustadz HR dipandang sebagai sosok inspirasi yang diteladani dan dihormati dilingkungan tersebut. Kedua, metode yang digunakan adalah metode pembiasaan. Hal ini terlihat dari kegiatan yang dilaksanakan oleh ustadz bersama para remaja seperti aksi kebersihan yang rutin dilaksanakan di Desa Darussalam. Hal ini senada dengan pendapat Heri Gunawan bahwa metode pembiasaan yang digunakan dalam menanamkan suatu kebiasaan atau tingkah laku bagi anak didik (Heri Gunawan, 2014).

Pembiasaan yang dilakukan oleh ustadz kepada para remaja agar para remaja mempunyai rasa peduli dan tanggung jawab terhadap Al-Fikri: Jurnal Studi dan Penelitian Pendidikan Islam Vol. 04 No. 02 (2021) : 117 -126

Available online at http://jurnal.unissula.ac.id/index.php/fikri/issue/archive 
lingkungan sekitarnya. Ketiga, metode yang digunakan adalah metode cerita. Hal ini terlihat dari penyampaian ustadz yang selalu menggunakan cerita dalam menyampaikan materi. Senada dengan pendapat Zainab bahwa metode cerita bisa bisa disebut dengan kisah atau dongeng yang dapat ditanamkan berbagai macam nilai-nilai keagamaan agar menambah pemahaman kepada si pendengar terhadap penyampaian yang disampaikan oleh pengajarnya (Zainab, 2012).

Adapun metode yang digunakan oleh ustadz HR untuk memudahkan para remaja dalam memahami materi yang disampaikan. Sebab jika tidak, internalisasi nilai-nilai yang ditanamkan akan sulit diserap oleh para remaja. Keempat, metode yang digunakan adalah metode ceramah. Hal ini terlihat dari penyampaian oleh ustadz HR. Priliansyah menguatkan bahwa suatu proses mengajar yang digunakan dalam memberikan materi secara langsung melalui lisan. Hal ini dianggap efektif untuk memberi penegasan terhadap materi yang disampaikan. (Priliansyah Ma'ruf Nur, n.d.).

Kelima, metode yang digunakan adalah metode demonstrasi atau praktik langsung. Metode demonstrasi yang dilakukan ustadz HR seperti memberikan contoh dari materi yang disampaikan agar menambah pemahaman remaja terkait apa yang disampaikan dalam majelis ta'lim. Hal ini selaras juga dengan pendapat Nuraini bahwa metode demontrasi merupakan cara penyampaian materi pembelajaran dengan cara menunjukkan proses pelaksanaan materi yang disajikan tersebut secara langsung di depan remaja sehingga dapat disaksikan secara langsung dan bisa dipahami serta ditiru (Nuraini, 2019)

Ketiga materi internalisasi nilai adalah materi yang diajarkan oleh ustadz HR yaitu Kitab Riyadus Shalihin dan Kitab Hidayatus Salikin yang di dalamnya terdapat nilai akidah, nilai ibadah dan nilai akhlak yang diinternalisasikan kepada para remaja.

Nilai akidah merupakan nilai yang pertama ditanamkan oleh ustadz HR kepada para remaja. Dari nilai akidah yang ditanamkan meliputi keimanan dan ketakwaan kepada Allah SWT seperti ketaatan kepada Allah dari untuk beribadah sholat berjamaah lima waktu dan selalu bersholawat kepada Nabi dan selalu menambah kecintaan kepada Rasulullah SAW. melului sholawat kepadanya. Hal ini senada dengan pendapat Mawardi akidah sebagai sebuah keyakinan akan membentuk tingkah laku, bahkan mempengaruhi kehidupan seorang muslim (Imam Sibaweh Al-Mawardi, 2019). 
Bentuk nilai akidah yang ditanamkan kepada remaja adalah tentang rukun iman dan mencintai Rasulullah SAW. sebelum kegiatan majelis ta'lim dimulai, diawali dengan do'a, pembacaan shalawat kamilah dan maulid habsyi. Selain itu, sang ustadz juga sering memberi wejangan tentang penting menjaga shalat baik yang wajib atau sunah dan bersholawat kepada Nabi Muhammad SAW.

Nilai ibadah merupakan nilai kedua yang ditanamkan oleh ustadz kepada remaja. Nilai ibadah yang ditanamkan tentang fadhilat sholat berjamaah dan ibadah sunah serta membaca sholawat. Hal ini senada dengan pendapat Hamdanah bahwa ibadah merupakan bentuk rasa syukur yang dilakukan manusia kepada Tuhan. Ibadah adalah bagian yang sangat penting dari setiap agama atau kepercayaan. (Hamdanah and Rinaldy, 2017).

Adapun bentuk nilai ibadah yang ditanamkan seperti ibadah sholat lima waktu dan ibadah sunah serta sholawat yang harus diamalkan. Para remaja selalu diingatkan sholat waktu berjamaah tepat waktu di masjid dan selalu diingatkan untuk mengamalkan ibadah sunnah lainnya seperti sholat, puasa dan selalu bersholawat setiap harinya kepada Nabi Muhammad SAW. sebelum memulai pengajian ustadz HR selalu menanyakan tentang sholat kepada para remaja. Hal ini dilakukan untuk mengecek apakah para remaja telah melaksanakan shalat atau belum.

Nilai akhlak merupakan nilai ketiga yang ditanamkan oleh ustadz HR. Nilai akhlak berkaitan dengan perilaku manusia. Hal ini sesuai dengan pendapat Mawardi bahwa akhlak adalah sesuatu yang berhubungan kepada manusia, akhlak kepada Allah dan tata krama sosial. Akhlak adalah bentuk dari tabi'at, budi pekerti dan kebiasaan dari hasil akidah dan ibadah (Imam Sibaweh Al-Mawardi, 2019).

Adapun bentuk nilai akhlak yang ditanamkan yaitu berprilaku yang baik kepada Allah, kepada orang tua dan peduli dengan lingkungan sekitar. Kemudian para remaja mengalami banyak perubahan dari segi akhlak yang menjadi lebih baik dan amal perbuatanya juga baik. Hal ini terihat dari sikap para remaja yang menjadi rajin dalam beribadah dan mengikuti kegiatan maulid habsyi.

Dalam Internalisasi nilai-nilai pendidikan keagamaan remaja pada majelis ta'lim juga dipengaruhi oleh faktor-faktor pendukung dan penghambat. Faktor yang mempengaruhi ustadz HR dalam internalisai nilai-nilai pendidikan keagamaan remaja pada majelis ta'lim, yaitu: latar belakang pendidikan dan lingkungan masyarakat. Adapun faktor Al-Fikri: Jurnal Studi dan Penelitian Pendidikan Islam Vol. 04 No. 02 (2021) : 117 -126 
penghambatnya yaitu: pergaulan remaja dan, keterbatasan fasilitas. Berdasarkan hasil analisis peneliti, faktor pendukung dan penghambat internalisasi nilai dirincikan sebagai berikut:

Pertama faktor pendukungnya ustadz HR menunjukkan tidak ada masalah dalam kapasitas diri ustadz HR selaku ustadz di Desa Darussalam tersebut. Hal ini didukung dengan latar belakang pendidikan S2 ustadz HR, serta merupakan alumnus sekolah tingkat madrasah sampai S1 di Pondok Pesantren Rasyilidiyah Rakha Amuntai, Kota Amuntai, Provinsi Kalimantan Selatan. Berdasarkan latar belakang pendidikannya, ustadz HR menyatakan kredibilitas ini bukan sebagai faktor penghambat.

Sedangkan lingkungan masyarakat juga merupakan faktor pendukung dalam kegiatan majelis ta'lim. Adapun peneliti temukan dilapangan bahwa terdapat dukungan dari para masyarakat dan orang tua dalam kegiatan majelis ta'lim yang menjadi faktor pendukung dalam menanamkan nilai-nilai pendidikan keagamaan kepada remaja. selain itu dukungan masyarakat ini juga sangat membantu ustadz HR dalam menanamkan nilai-nilai pendidikan keagamaan remaja.

Kedua mengenai faktor penghambatnya menurut bapak $\mathrm{YH}$ selaku ketua RT 2 mengatakan bahwa antusias remaja dalam mengikuti majelis ta'lim berkurang karena terpengaruh oleh teman-teman yang ada disekitar rumah seperti bermain game. Faktor tersebut yang menyebabkan remaja malas untuk berhadir pada majelis ta'lim. Game dan gadget saat ini memang menjadi tantangan tersendiri bagi remaja. Disamping itu orang tua juga harus lebih waspada terhadap bahaya bermain game dan kecanduan bermain gadget.

Sedangkan keterbatasan fasilitas pada kegiatan yang dilaksanakan di rumahnya. Karena tidak adanya bantuan dari desa, dikarenakan majelis ta'limnya bersifat pribadi sehingga tidak ada bantuan dari desa. Mengenai faktor penghambat, hal ini juga dibenarkan oleh bapak YH selaku ketua RT 2 mengatakan bahwa tidak adanya fasilitas gerobak untuk mengangkut barang atau alat dari group habsyi yang dibina oleh ustadz HR sehingga harus meminjam gerobak di tempat lain. Proses internalisasi dalam menanamkan nilai-nilai agama pada remaja juga membutuhkan peran dari orang tua dan organisasi keagamaan. Sebagai wujud totalitas internalisasi nilai-nilai agama maka keluarga merupakan lingkungan pertama (Surawan, 2019).

\section{Kesimpulan}

Al-Fikri: Jurnal Studi dan Penelitian Pendidikan Islam

Vol. 04 No. 02 (2021) : $117-126$

Available online at http://jurnal.unissula.ac.id/index.php/fikri/issue/archive 
Adapun kesimpulan dalam internalisasi nilai-nilai pendidikan keagamaan remaja melalui majelis ta'lim di Desa Darussalam Kecamatan Danau Panggang bahwa tujuan internalisasi nilai untuk menanamkan nilai-nilai pendidikan keagamaan remaja agar memiliki sikap dan prilaku yang baik. Metode internalisasi nilai yang digunakan adalah keteladanan, pembiasaan, cerita, ceramah dan dokumentasi. Dalam materi internalisasi nilai meliputi nilai akidah, ibadah dan akhlak. Nilai akidah yang ditanamkan adalah tentang keyakinan dan keimanan kepada Allah dan kecintaan kepada Nabi Muhammad SAW. Nilai ibadah yang ditanamkan adalah ibadah sholat wajib dan ibadah sunah lainnya. Nilai akhlak yang ditanamkan adalah akhlak kepada Allah, Rasulullah, orang tua dan peduli dengan lingkungan sekitar. 


\section{Daftar Pustaka}

Bahtiar, Ghufron. (2015). “Pembinaan Keagamaan Remaja Islam Dalam Meningkatkan Akhlak Melalui Kajian Sabtu Malam Di Dusun Ngipiksari." Skripsi UIN Sunan KaliJaga Yogyakarta.

Gunawan, Heri. (2014). Pendidikan Islam Kajian Teoritis Dan Pemikiran Tokoh. Bandung: Remaja Rosdakarya.

Hamdanah, hamdanah, and rinaldy Rinaldy. (2017). Nilai-Nilai Pendidikan Islam. Banjarmasin: Pustaka Banua.

Imam Sibaweh Al-Mawardi. (2019). "Model Pembelajaran Pendidikan Perdamaian (Kajian al-Qur'an Surat An-Nahl)." Rahmatan Lil Alamin Journal of Peace Education and Islamic Studies 2, no. 1: 1-40.

Ma'ruf Nur, Priliansyah. (n.d.)“Internalisasi Nilai-Nilai Pendidikan Agama Islam Melalui Ekstrakurikuler Rohaniah Islam (Rohis) Untuk Pembentukan Kepribadian Muslim Siswa SMA 1 Banjarnegara." Skripsi UIN Walisongo Semarang.

Muslimah, Muslimah. (2015)."Pendidikan Nilai Religius Dalam Keluarga (Upaya Penanaman Nilai Tanggung Jawab, Serial Studies Usia Anak) Di Pangkalan Bun." Disertasi Pascasarjana IAIN Antasari Banjarmasin.

Nuraini, Nuraini. (2019). “Internalisasi Nilai-Nilai Pendidikan Agama Islam Pada Kegiatan Ekstrakurikuler Rohaniah Islam Dalam Membina Karakter Peserta Didik Di SMA Negeri 1 Air Putih Kabupaten Batu Bara." Jurnal Ansiru PAI 3, no. 2.

Pemerintah Republik Indonesia, (2007). Undang-undang nomor 55. “Undang-Undang Peraturan Pemerintah Republik Indonesia Nomor 55 Tahun 2007.

Surawan, Surawan. (2019). “Pola Internalisasi Nilai Keislaman Keluarga Muhammadiyah Dan Islam Abangan." Jurnal Hadratul Madaniyah 6, no. 2.

Warsiyah, W. (2018). Pembentuk Religiusitas Remaja Muslim (Tinjauan Deskriptif Analitis). Cendekia: Jurnal Kependidikan dan Kemasyarakatan, 16(1), 19-40. 
Zainab, Zainab. (2012). "Peningkatan Perkembangan Moral Anak Melalui Metode Cerita Bergambar TK Lembah Sari Agam"." Jurnal Pesona Paud 1, no. 3. 